\title{
Радиационная стойкость терагерцовых диодов на основе GaAs/AIAs-сверхрешеток
}

\author{
(ㄱ Д.Г. Павельев ${ }^{1}$, А.П. Васильев ${ }^{2}$, В.А. Козлов ${ }^{1,3}$, Е.С. Оболенская ${ }^{1, q}$ \\ ${ }^{1}$ Нижегородский государственный университет им. Н.И. Лобачевского, \\ 603950 Нижний Новгород, Россия \\ ${ }^{2}$ Научно-технологический центр микроэлектроники и субмикронных гетероструктур Российской академии наук, \\ 194021 Санкт-Петербург, Россия \\ ${ }^{3}$ Институт фоизики микроструктур Российской академии наук, \\ 603087 Нижний Новгород, Россия \\ IE-mail: bess009@mail.ru
}

(Получена 25 апреля 2018 г. Принята к печати 7 мая 2018 г.)

\begin{abstract}
Впервые теоретически и экспериментально исследована радиационная стойкость к гамма-нейтронному облучению ( 1 МэB) диодов на основе симметричных GaAs/AlAs 30-периодных сверхрешеток. В расчетах использованы модельные зонная диаграмма и эквивалентная схема исследуемой структуры. Расчеты проведены в квазигидродинамическом приближении с учетом разогрева исследуемых диодов протекающим током. Результаты расчетов ВАХ и предельных частот работы диодов до и после гамма-нейтронного облучения хорошо коррелируют с экспериментальными данными.
\end{abstract}

DOI: $10.21883 /$ FTP.2018.11.46595.17

\section{1. Введение}

Исследование радиационной стойкости полупроводниковых приборов является важным звеном проектирования специальных радиоэлектронных систем. Предполагается, что источниками быстрых нейтронов ( 1 МэВ) могут являться ядерный взрыв или ядерные реакторы. При попадании быстрого нейтрона в ядро атома решетки полупроводника выбивается первичный атом отдачи, приводящий к каскаду смещений до 1000 вторичных атомов. Структура каскада смещенных атомов подобна виноградной грозди $[1-4,5]$, причем в роли „виноградин“ выступают плотные скопления радиационных дефектов. Спустя характерное время стабилизации радиационных дефектов (от единиц фемтосекунд до единиц пикосекунд и более) формируются стабильные кластеры радиационных дефектов (30-300 нм), состоящие из плотных субкластеров дефектов (5-30 нм). Рассеяние на таких субкластерах мешает движению электронов и ухудшает характеристики прибора [1-4]. До сих пор основные процессы формирования кластера радиационных дефектов при нейтронном облучении детально экспериментально не исследованы, так как длительность указанного процесса $10^{1}-10^{4}$ фс, что соответствует частотам 0.1-100 ТГц. Решение указанной задачи позволит лучше понять процессы, протекающие в современных СВЧ приборах, использующихся в военной и специальной технике.

Ранее [6] была предложена идея использовать для регистрации фемтосекундных процессов формирования кластера радиационных дефектов терагерцовые диоды. Для этого был проведен теоретический анализ процессов формирования и стабилизации кластера радиационных дефектов в диоде при попадании быстрого нейтрона в область пространственного заряда этого полупроводникового диода. Рассчитан импульс тока, фор- мируемый вторичными электронами, и определен спектр сигнала, генерируемого диодом (как детектором) при воздействии импульсного потока нейтронов из спектра деления. Перечисленные процессы качественно рассматривались в модельном диоде [6], поэтому в данной работе, для сравнения с проводимым экспериментом, было необходимо построить модель транспорта электронов в конкретном диоде и выяснить может ли он быть претендентом на использование для описанных целей. Важно, что для использования такого диода в экспериментах он должен быть достаточно радиационно стойким.

В связи с указанным, в качестве объекта исследования выбраны терагерцовые планарные диоды на сильно легированных 30-периодных GaAs/AlAs-сверхрешетках (CP). Такие диоды имеют высокие предельные частоты и необходимые экспериментальные характеристики, однако их радиационная стойкость еще не изучалась. В [7-11] нами экспериментально исследовались диоды на основе 6-, 18- и 30-периодных GaAs/AlAs-сверхрешеток (CP), были определены характеристики омических контактов, измерены вольт-амперные характеристики, проведено моделирование транспорта электронов в исследуемых диодах.

В настоящей работе путем моделирования в квазигидродинамическом приближении [12] и методом Монте-Карло [12,13] изучается транспорт электронов в диодах на основе 30-периодных СР до и после как нейтронного, так и $\gamma$-нейтронного облучения. В статье предложена уточненная структура зонной диаграммы и эквивалентной схемы исследуемых диодов. Была создана новая математическая модель, позволяющая рассчитывать температуру активной области диодов, разогретых протекающим током с учетом наличия кластеров радиационных дефектов, возникших из-за воздействия быстрых нейтронов. Проведены измерения вольт-амперных характеристик до и после нейтронного облучения. Определен 


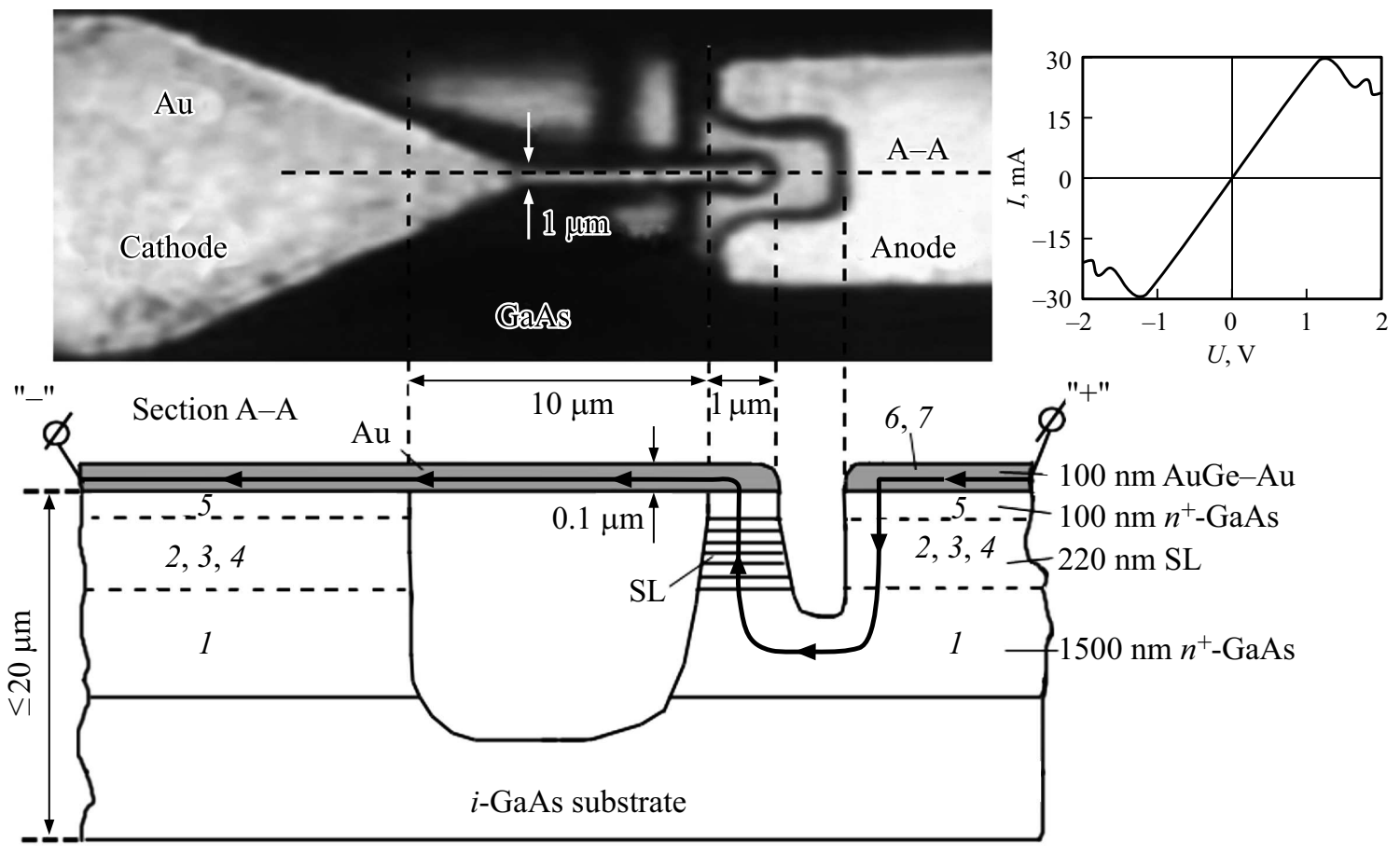

Рис. 1. Конструкция исследуемой структуры [7,11]. Меткой „SL“ и штриховкой отмечена рабочая область диода со сверхрешеткой, в которой реализуется большая плотность тока. Эта область определяет электрические параметры диода. Места гетероструктуры с малой плотностью тока не играют принципиальной роли в работе диода. Линией со стрелками показано прохождение электронов в диоде: по металлическому контакту катода, через рабочую область, и далее в контакт анода. Цифрами обозначены: $1,5-$ сильно легированные контактные слои $n^{+}$-GaAs с концентрацией донорной примеси $\sim 5 \cdot 10^{18} \mathrm{~cm}^{-3} ; 2,4-$ переходные градиентные слои $\mathrm{AlAs} / \mathrm{GaAs} ; 3$ - активная область, т. е. 30-периодная GaAs/AlAs-сверхрешетка, легированная до $10^{18} \mathrm{~cm}^{-3} ; 6-$ подконтактный слой InGaAs; 7 - контактный слой, состоящий из AuGe и Au.

уровень радиационной стойкости исследуемых диодов. Экспериментально обнаружено частичное восстановление параметров исследуемых диодов после нейтронного облучения за счет отжига радиационных дефектов под действием нагрева их протекающим током. С точки зрения исследования процессов формирования кластера радиационных дефектов восстановление рабочего тока диодов важно для сохранения излучаемой ими мощности, что необходимо для проведения экспериментов.

\section{2. Объект исследования}

Для исследований методом молекулярно-лучевой эпитаксии [11] были изготовлены планарные диодные структуры на 30-периодной СР, каждый период которых состоял из 18 монослоев GaAs и 4 монослоев AlAs. С помощью фотолитографии, химического травления и электроосаждения металлов были изготовлены диоды с площадью активной области 1 мкм $^{2}$ (рис. 1). Для эффективного ввода электронов в СР на ее краях были сформированы переходные слои, состоящие из чередующихся слоев AlAs и GaAs с толщинами $1 \times 28,2 \times 24$ и $3 \times 21$ монослоев [10].

На рис. 1 представлена конструкция исследуемых планарных структур: вид сверху (фото) и сбоку (разрез).
Линией со стрелками на рисунке показан маршрут протекания тока в диоде: по металлическому контакту, через СР и затем в другой металлический контакт. Важно, что диод разделен глубоко протравленной канавкой так, что весь основной ток, протекающий через СР, сосредоточен в одном месте, которое указано меткой: „SL“ - это рабочая область диода. Другие области сверхрешетки имеют большие площади сечения и не оказывают существенного влияния на работу диода.

Итоговая исследуемая структура состояла из последовательно осажденных слоев [7], изображенных на рис. 1 снизу вверх.

1. Нижний сильно легированный слой $n^{+}$-GaAs c концентрацией донорной примеси $\sim 5 \cdot 10^{18} \mathrm{~cm}^{-3}$ (анод диода).

2. Нижний переходный градиентный слой, отделяющий активную область от сильно легированного слоя, в виде гетероструктуры AlAs/GaAs с постепенным увеличением толщины барьеров и снижением уровня легирования.

3. GaAs/AlAs-сверхрешетка, состоящая из 30 периодов, каждый из которых состоит из 18 монослоев GaAs и 4 монослоев AlAs, легированная до $10^{18} \mathrm{~cm}^{-3}$. Это активная область гетероструктуры.

4. Верхний переходный градиентный слой, отделяющий активную область от сильно легированного слоя, в 
виде гетероструктуры AlAs/GaAs с постепенным уменьшением толщины барьеров и увеличением уровня легирования.

5. Верхний сильно легированный контактный слой $n^{+}$-GaAs c концентрацией донорной примеси $\sim 5 \cdot 10^{18} \mathrm{~cm}^{-3}$ (катод диода).

6. Подконтактный слой InGaAs, в котором мольная доля InAs и концентрация донорной примеси линейно увеличиваются.

7. Контактный слой, состоящий из $\mathrm{AuGe}$ и $\mathrm{Au}$. На этом слое сформированы анодный и катодный контакты диода.

\section{3. Моделирование}

Ранее нами исследовался транспорт в диодах на основе 30-периодных GaAs/AlAs CP по упрощенной схеме [11], не учитывающей специальных переходных областей, примыкающих к активной области диода [8]. Также не учитывался разогрев диода протекающим током при больших амплитудах напряжений питания и(или) сигнала.

В настоящей работе на основе подхода [4] была построена новая математическая модель, в которой были учтены разогрев рабочей области диодов протекающим током, а также влияние кластеров радиационных дефектов (КРД) на электрические параметры диодов.

Расчет структуры КРД проводился с использованием метода Монте-Карло с помощью алгоритма SRIM [14]. Были получены характеристики каскадов смещений, усреднение и анализ которых позволяют найти статистические моменты функций распределения параметров кластеров и субкластеров радиационных дефектов (КРД и СКРД). Далее, исходя из полученных данных проводилось моделирование транспорта электронов в полупроводниковых приборах до и после нейтронного облучения в квазигидродинамическом приближении и методом Монте-Карло. Плотность тока электронов рассчитывалась с учетом рассеяния электронов на КРД в приближении потенциала Госсика. Также на частоты рассеяния электронов влиял разогрев полупроводниковой структуры протекающим током, который учитывался с помощью оригинального аналитического подхода.

На рис. 2 представлена часть зонной диаграммы для активной области диода на основе GaAs/AlAs-сверхрешетки, состоящей из 30 периодов, каждый из которых состоит из 18 монослоев GaAs и 4 монослоев AlAs. На вставке представлена зонная диаграмма для всей рабочей области (слои 2, 3, 4 на рис. 1 в разд. 2), с учетом переходных слоев. В приближении плоского конденсатора была оценена емкость одного барьера, которая составила 40 фФ.

Было рассчитано сопротивление в яме и барьере при подаче внешнего напряжения на исследуемый диод. Сопротивление слоя, формирующего квантовую яму, оценивалось исходя из значения проводимости GaAs. Сопротивление слоев, формирующих барьер, - исходя
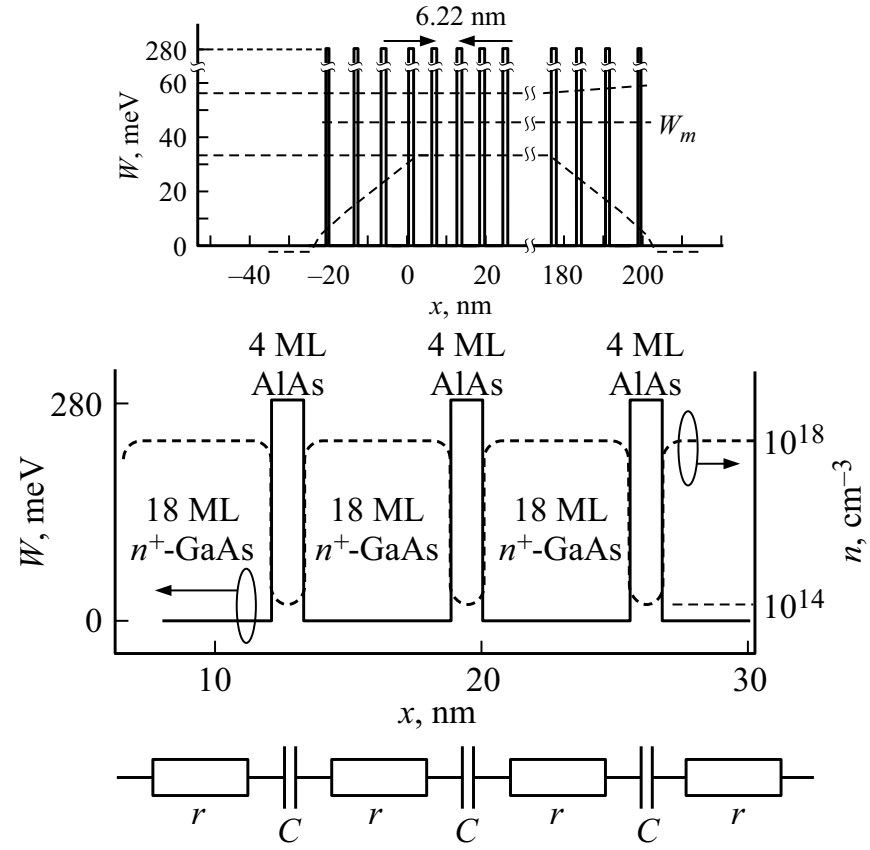

Pис. 2. Часть зонной диаграммы без внешнего напряжения для активной области диода на основе GaAs/AlAs-сверхрешетки, состоящей из 30 периодов (каждый из которых состоит из 18 монослоев GaAs и 4 монослоев AlAs). Далее представлена эквивалентная схема активной области, состоящая из последовательно включенных сопротивлений $r$ и емкостей $C=40 \phi \Phi$. Сверху, на вставке представлена зонная диаграмма для всей активной области с учетом переходных слоев. Концентрация электронов $n(x)$ в слоях сверхрешетки на части зонной диаграммы показана пунктиром. $W_{m}-$ положение середины минизоны.
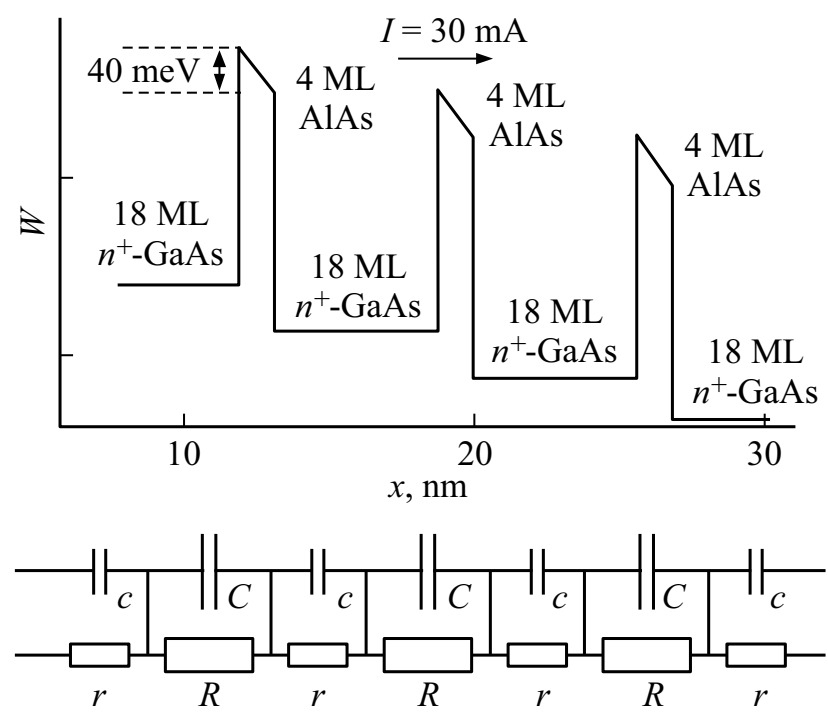

Рис. 3. Часть зонной диаграммы активной области диода на основе $\mathrm{GaAs} / \mathrm{AlAs}$-сверхрешетки при подаче внешнего напряжения. Далее представлена эквивалентная схема активной области, состоящая из сопротивлений $(R=1.3$ Ом - сопротивление барьера, $r=0.18$ Ом - сопротивление ямы, $r \ll R)$ и емкостей $C, c$. 
из экспериментального значения сопротивления диода. Получено, что сопротивление барьеров много больше, чем ям, т.е. все падение приложенного напряжения приходится на барьеры. Наклон потенциала зонной диаграммы в сильно легированных ямах незначителен по сравнению с наклоном в барьерах с низкой концентрацией электронов (рис. 3). Исходя из сопротивления и емкости активной области диода, определенных согласно эквивалентной схеме, предельная частота работы: $1 /(2 \pi R C) \approx 3$ ТГц (общее сопротивление диода 40 Ом, суммарная емкость диода около $1 ф \Phi)$. Данная оценка хорошо коррелирует с экспериментальными данными о предельных частотах терагерцовых детекторов и умножителей, построенных на таких диодах, о чем ранее нами сообщалось в [9]. Моделирование BAX диодов с помощью подхода [4] показало, что приведенные выше аналитические оценки хорошо совпадают с результатами численных расчетов, поэтому предложенная эквивалентная схема может быть использована и для обсуждения поведения диодов после радиационного облучения.

\section{4. Моделирование радиационной стойкости диода}

С точки зрения практического применения аналогами исследуемых диодов на основе СР являются диоды Шоттки и диоды Ганна, чья радиационная стойкость известна из литературы [15,16-18]. Диод Ганна является аналогом с точки зрения генерации СВЧ сигналов, а диод Шоттки с точки зрения умножения. Однако предельные частоты функционирования указанных диодов лежат в диапазоне ниже 1 ТГц, что не позволяет их использовать для исследования процессов формирования кластеров радиационных дефектов.

В традиционных „объемных“ диодах Ганна $[16,17]$ при достижении порогового значения поля в структуре формируется область сильного поля (домен), который движется от катода к аноду со скоростью $\sim 10^{7} \mathrm{~cm} / \mathrm{c}$. Когда домен формируется, ток падает, а при исчезновении домена, ток возрастает. Механизм возникновения отрицательной дифференциальной проводимости на вольт-амперной характеристике связан с междолинными переходами, и домен формируется в течение 3-5 времен свободного пробега при междолинном рассеянии. Радиационное воздействие сильно влияет на работу таких диодов, так как радиационные дефекты снижают концентрацию и подвижность электронов, что приводит к катастрофическому уменьшению выходной мощности диодов Ганна уже при флюенсах нейтронного излучения $\sim 10^{13} \mathrm{H} / \mathrm{cm}^{2}$.

Последние исследования [12] показывают, что для диодов Ганна возможна работа на частотах до 0.5 ТГц при условии планарной архитектуры устройства диода Ганна и использования свойств двумерного электронного газа для увеличения быстродействия. В [12] было показано, что структуры с двумерным газом дают на порядок бо́льшую радиационную стойкость за счет большей

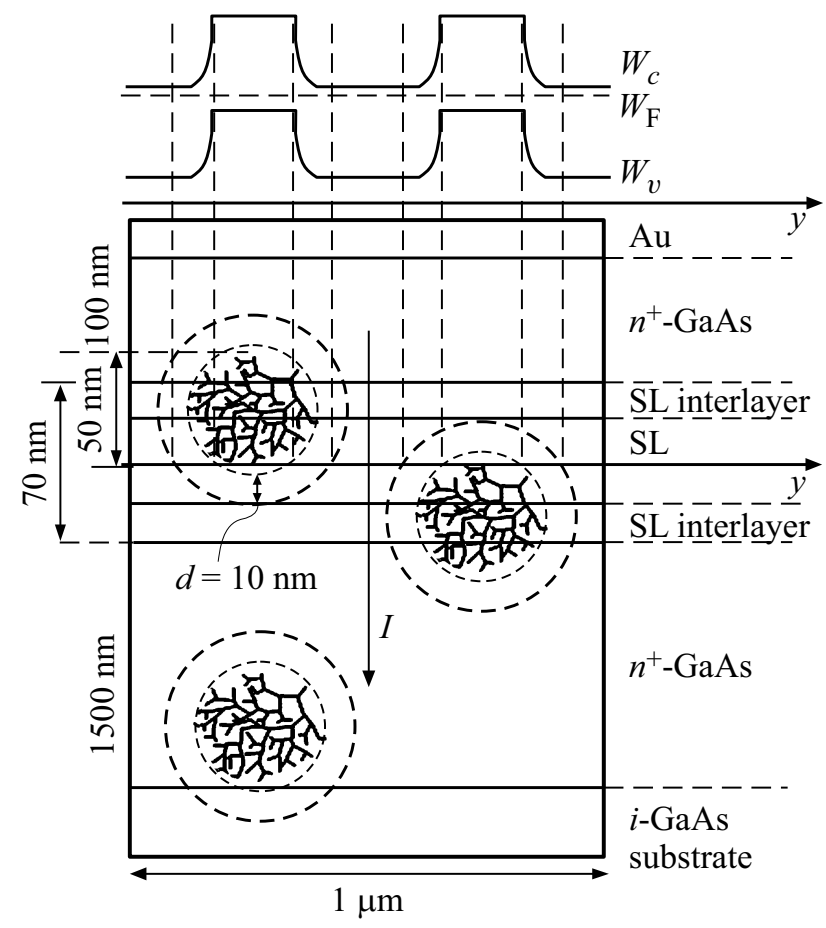

Рис. 4. Схематичное изображение кластеров радиационных дефектов в исследуемом диоде на основе сверхрешетки, а также вид зонной диаграммы кластеров дефектов согласно хорошо известной модели Госсика [21]. Указана ширина области пространственного заряда вокруг кластеров радиационных дефектов $d=10$ нм.

концентрации электронов по сравнению с „объемными“ диодами Ганна. Это объясняется тем, что необходимо большее количество радиационных дефектов, чтобы существенно изменить концентрацию электронов за счет их захвата на ловушки.

В исследуемых в данной работе диодах на основе CP процесс формирования отрицательной дифференциальной проводимости принципиально иной, он связан с отражением электронов от потолка энергетической мини-зоны и блоховскими осцилляциями. Длина активной области исследуемых диодов по размеру сравнима с кластером радиационных дефектов. Таким образом, транспорт электронов после радиационного воздействия будет связан с проводимостью между субкластерами дефектов [19].

Кластеры радиационных дефектов образуются в активной области диода, и, согласно модели Госсика, такой кластер, за счет наличия области пространственного заряда (ОП3), препятствует движению электрона (рис. 4). Соответственно ток будет протекать в области между субкластерами радиационных дефектов. Поскольку размеры диода в вертикальном направлении намного больше, чем размеры и расстояние между СКРД, то в диоде их убирается много. Такой тип транспорта электронов в сверхрешетках ранее не изучался.

C помощью известного алгоритма SRIM [4,14] получено, что при попадании в ядро атома гетероструктуры 
Таблица 1. Размер, концентрация и расстояния между кластерами дефектов, а также доля поперечной площади диода, блокированной кластерами дефектов в зависимости от флюенса нейтронов

\begin{tabular}{|c|c|c|c|c|}
\hline $\begin{array}{c}\text { Флюенс } \\
\text { нейтронов, н/см² }\end{array}$ & $\begin{array}{c}\text { Концентрация } \\
\text { СКРД, } \mathrm{cm}^{-3}\end{array}$ & $\begin{array}{c}\text { Среднее количество } \\
\text { кластеров в сверхрешетке } \\
\text { (Среднее количество кластеров } \\
\text { в активной области диода) }\end{array}$ & $\begin{array}{l}\text { Расстояние между } \\
\text { краями СКРД } \\
\text { для горячих } \\
\text { электронов, нм }\end{array}$ & $\begin{array}{c}\text { Доля поперечной площади } \\
\text { диода, блокированной } \\
\text { кластерами радиационных } \\
\text { дефектов, \% }\end{array}$ \\
\hline $10^{12}$ & $2 \cdot 10^{11}$ & $0(0)$ & 1640 & $0(0)$ \\
\hline $10^{13}$ & $2 \cdot 10^{12}$ & $2(8)$ & 724 & $3(10)$ \\
\hline $10^{14}$ & $2 \cdot 10^{13}$ & $12(30)$ & 298 & $15(41)$ \\
\hline $10^{15}$ & $2 \cdot 10^{14}$ & $57(142)$ & 101 & $37(90)$ \\
\hline $3 \cdot 10^{15}$ & $6 \cdot 10^{14}$ & $117(292)$ & 49 & $77(100)$ \\
\hline $6 \cdot 10^{15}$ & $1.2 \cdot 10^{15}$ & $188(470)$ & 24 & $100(100)^{*}$ \\
\hline $6.5 \cdot 10^{15}$ & $1.3 \cdot 10^{15}$ & $200(500)$ & $\mathbf{0}$ & Кластеры касаются \\
\hline отказ & отказ & отказ & отказ & друг друга \\
\hline
\end{tabular}

Примечание. * На проекции изображения кластеров на плоскости поперечного сечения активной области диода нет зазоров между кластерами.

одного быстрого нейтрона $(1 \mathrm{MэB)} \mathrm{возникают} \mathrm{атомы}$ отдачи, которые формируют кластеры радиационных дефектов. Каждый кластер состоит из $10^{2}-10^{4}$ точечных дефектов, объединившихся в комплексы [16,20,21]. Количество кластеров дефектов зависит от уровня облучения и может составлять от единиц до $10^{3}$ штук в активной области диода (рис. 4). Характерные размеры стабильных кластеров слабо отличаются от размеров, которые получаются в ходе расчетов по SRIM в силу малых коэффициентов диффузии дефектов при комнатных температурах [22].

Был проведен расчет размеров, концентрации и расстояний между кластерами радиационных дефектов (табл. 1). Из результатов расчета видно, что при флюенсах облучения $\sim 10^{13} \mathrm{~cm}^{-2}$ величина амплитуды тока уменьшается примерно на 10\%. Изменение амплитуды тока в максимуме на вольт-амперной характеристике соответствует поперечной площади рабочей области диода, блокированной кластерами, что хорошо коррелирует с экспериментальными данными, которые будут представлены далее (разд. 6).

Заметим, что концентрация точечных дефектов, генерируемых как нейтронным, так и $\gamma$-облучением с флюенсами до $10^{14} \mathrm{~cm}^{-2}$ и дозами до $10^{5}$ рад, составляет $10^{16}-10^{17} \mathrm{~cm}^{-3}$, что на порядок меньше, чем концентрация ионов доноров в исследуемых диодах. Указанное обусловливает слабое влияние точечных радиационных дефектов на работу как исследуемых сверхрешеток, так и других СВЧ полупроводниковых приборов (полевых транзисторов Шоттки, НЕМТ и др.) с высоким легированием активной области, что коррелирует с данными [16].

Моделирование транспорта электронов в квазигидродинамическом приближении и методом Монте-Карло согласно модели [11] показало, что в диодах на основе 30-периодных СР радиационное воздействие сильно влияет на ту область активной части диода, где движется „блоховский“ домен. При этом уменьшение амплитуды тока диодов практически совпадало с результатами оценки по данным табл. 1 и хорошо коррелировало с экспериментальными данными. На этой основе был сделан вывод об адекватности аналитического подхода, предложенного в данной работе для описания изменения параметров диодов после $\gamma$-нейтронного облучения.

\section{5. Температурный режим диода под внешним напряжением}

Для описания и расчета нагрева диодов протекающим током использовалась тепловая эквивалентная схема, представленная на рис. 5, где указаны 4 тепловых со-

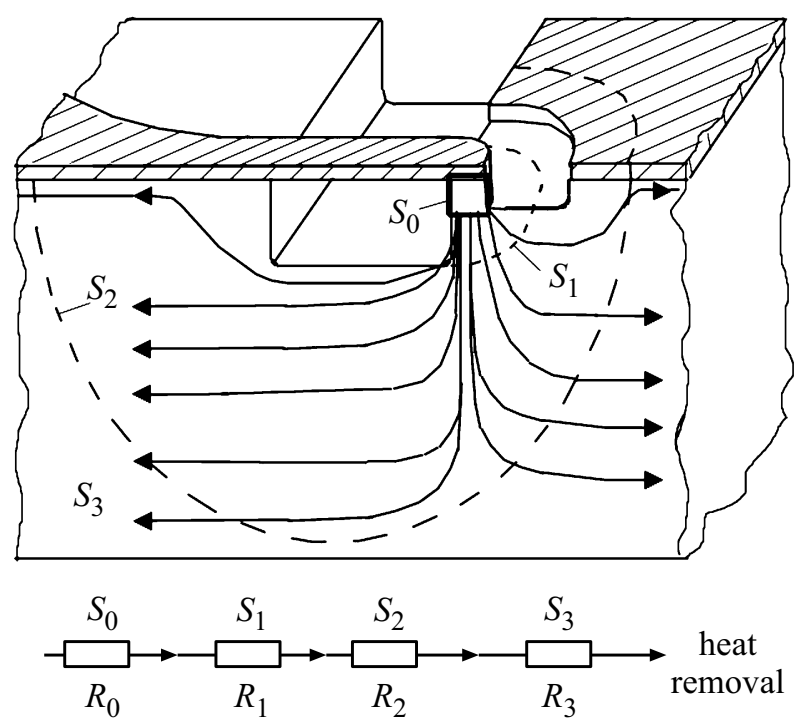

Рис. 5. Тепловая модель исследуемого диода на основе сверхрешетки (сечение А-А, см. рис. 1). Указаны 4 области диода: цилиндр $S_{0}$, четверть сферы $S_{1}$, половина сферы $S_{2}$ и параллелепипед $S_{3}$, которые соответствуют четырем тепловым $\left(R_{0}, R_{1}, R_{2}, R_{3}\right)$ сопротивлениям на эквивалентной схеме. Стрелками отмечено направление теплового потока, возникающего за счет выделения тепла при протекании электрического тока по областям $S_{0}-S_{3}$. Затем тепло отводилось к балочным выводам диода и далее в теплоотвод. 
Таблица 2. Статистика образцов, подверженных радиационному воздействию

\begin{tabular}{l|c|c|c}
\hline \multicolumn{1}{c|}{ Параметры облучения } & Флюенс нейтронов н/см & Доза $\gamma$-квантов, рад & Количество образцов \\
\hline Импульсный ядерный реактор, длительность & & & \\
импульса $\tau_{\text {imp }}=1$ мс, средняя энергия нейтронов & $2 \cdot 10^{12}$ & $\sim 10^{3}$ & 5 \\
1 МэВ, колоколообразный энергетический спектр. & $10^{13}$ & $\sim 10^{4}$ & 5 \\
Импульсное $\gamma$-излучение ядерного реактора, & $10^{14}$ & $\sim 10^{5}$ & 5 \\
средняя энергия $\gamma$-квантов 1 МэВ & - & $\sim 10^{3}$ & \\
\hline Статическое $\gamma$-излучение & - & $\sim 10^{4}$ & 5 \\
(рентгеновская трубка), & - & $\sim 10^{5}$ & 5 \\
средняя энергия $\gamma$-квантов 1 МэВ & - & $\sim 10^{6}$ & 5
\end{tabular}

противления $\left(S_{0}, S_{1}, S_{2}, S_{3}\right)$, соответствующие четырем областям в диоде. Внешние границы области $S_{0}$ - это границы активной области, форма которой близка к цилиндру. Внешние границы областей $S_{1}, S_{2}$ показаны пунктиром: $S_{1}$ - четверть сферы, $S_{2}$ - половина сферы. Область $S_{3}$ (подложка) представляет собой параллелепипед, через который тепло отводилось к балочным выводам диода и далее в теплоотвод.

По результатам расчета тепловой модели было получено тепловое сопротивление каждой области, которое для области $S_{0}$ (цилиндр) составило $1.4 \cdot 10^{3}{ }^{\circ} \mathrm{C} / \mathrm{B}$, для $S_{1}$ (четверть сферы) $-12.7 \cdot 10^{3}{ }^{\circ} \mathrm{C} / \mathrm{BT}$, для $S_{2}$ (половина сферы) $-3.5 \cdot 10^{3} \mathrm{C} / \mathrm{BT}$, для $S_{3}$ (параллелепипед) $1.04 \cdot 10^{3}{ }^{\circ} \mathrm{C} /$ Вт. Данные результаты получены для напряжения питания 2 В и тока диода $25 \mathrm{MA}$, которые использовались для процедуры отжига радиационных дефектов протекающим в диоде током (см. рис. 5). Температура нагрева области $S_{0}$ составляла $150-200^{\circ} \mathrm{C}$.

Отметим, что при работе диода в составе умножителя терагерцового сигнала $[10]$, когда величина рассеиваемой мощности на диоде имеет величину 5-10мВт, температура нагрева активной области диода составляет примерно $100-150^{\circ} \mathrm{C}$, что влияет на работу исследуемого диода. При работе в качестве детектора терагерцового сигнала [11] выделяемая мощность значительно меньше и разогревом диода можно пренебречь.

\section{6. Эксперимент и обсуждение результатов}

Для исследования влияния нейтронного облучения на диоды на основе СР в качестве основного источника использовался импульсный ядерный реактор, а в качестве дополнительного - источник $\gamma$-квантов (табл. 2). Так как ядерный реактор дает не только нейтронное, но и сопутствующее ему $\gamma$-излучение, необходимо было сопоставить влияние указанных типов излучения и отделить влияние нейтронного излучения от $\gamma$-излучения. Это делалось путем использования дополнительного источника и сопоставления результатов экспериментов по $\gamma$ и $\gamma$-нейтронному облучению. Отметим, что $\gamma$-облучение не формирует кластеры радиационных дефектов в полупроводниках, а генерирует только точечные дефекты за счет процессов фотоэффекта и эффекта Комптона [16].

При проведении эксперимента были измерены импульсные вольт-амперные характеристики (BАХ) диодов на основе 30-периодной сверхрешетки. Сначала импульсные ВАХ диодов измерялись до облучения. Потом диоды облучались $\gamma$-нейтронным и $\gamma$-облучением. После снижения наведенной радиоактивности в течение двух месяцев BAX измерялись еще раз, в тех же лабораторных условиях и на той же измерительной установке.

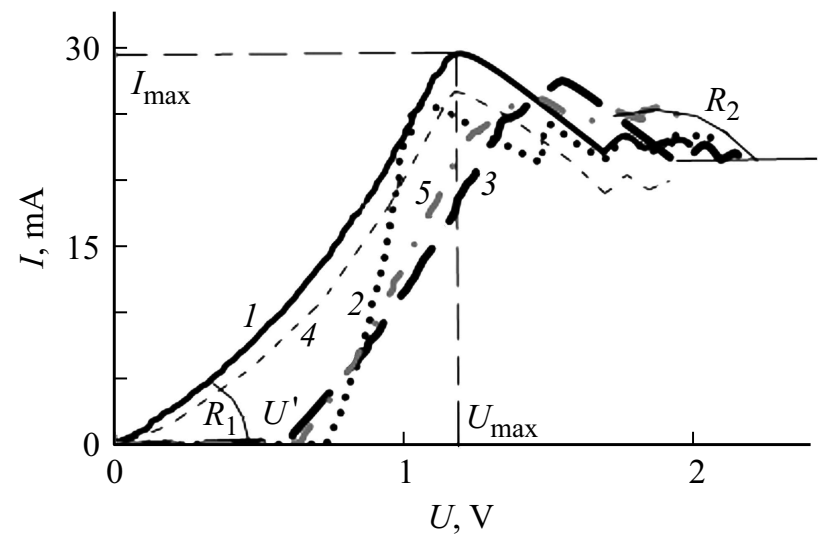

Рис. 6. Типичная вольт-амперная характеристика (BAX) исследуемых диодов на основе 30-периодной сверхрешетки до и после радиационного воздействия: 1 - до радиационного воздействия; 2 - после радиационного воздействия $\gamma$-нейтронным облучением с флюенсом $10^{13} \mathrm{H} / \mathrm{cm}^{2}$ и дозой $\gamma$-квантов $10^{4}$ рад; 3 - после радиационного воздействия $\gamma$-нейтронным облучением с флюенсом $10^{13} \mathrm{H} / \mathrm{cm}^{2}$ и дозой $\gamma$-квантов $10^{4}$ рад и отжига; $4-$ расчетная зависимость; $5-$ после радиационного воздействия дозой $\gamma$-квантов $10^{4}$ рад. Для $\gamma$-облучения с уровнями $10^{5}$ и $10^{6}$ рад кривые ВАХ имеют вид, аналогичный приведенной. Отмечены характерные параметры диодов: $I_{\max }, U_{\max }$ - ток и напряжение, соответствующие максимуму; $U^{\prime}$ - пороговое напряжение, при котором появляется заметный ток (после радиационного воздействия); $R_{1}$ - дифференциальное сопротивление начального участка вольт-амперной характеристики; $R_{2}$ - дифференциальное сопротивление участка отрицательной дифференциальной проводимости вольт-амперной характеристики. 
Таблица 3. Изменение параметров диодов после облучения нейтронами и $\gamma$-квантами $(\langle W\rangle=1 \mathrm{MэB})$

\begin{tabular}{|c|c|c|c|c|c|c|}
\hline \multirow{3}{*}{$\begin{array}{c}\text { Параметры } \\
\text { диодов }\end{array}$} & \multicolumn{3}{|c|}{ Без нейтронного облучения } & \multicolumn{3}{|c|}{ Флюенс нейтронов, н/см ${ }^{2}$} \\
\hline & \multicolumn{3}{|c|}{ Доза $\gamma$-квантов, рад } & \multicolumn{3}{|c|}{ Доза $\gamma$-квантов, рад } \\
\hline & $10^{5}$ & $10^{6}$ & $10^{7}$ & $2 \cdot 10^{12}, 10^{5}$ & $10^{13}, 10^{6}$ & $10^{14}, 10^{7}$ \\
\hline $\begin{array}{c}I_{\max }, \% \\
U_{\max }, \%, \\
R_{1}, \% \\
R_{2}, \% \\
U^{\prime}, \mathrm{B}\end{array}$ & $\begin{array}{c}-18(0) \\
3(0) \\
-14(0) \\
- \\
0.6\end{array}$ & $\begin{array}{c}-13(0) \\
5(0) \\
-32(0) \\
-21(0) \\
0.5\end{array}$ & $\begin{array}{c}-6(0) \\
19(0) \\
-15(0) \\
- \\
0.25\end{array}$ & $\begin{array}{c}-15(-0.3) \\
45(0) \\
34(-0.3) \\
-37(-0.15) \\
0.39\end{array}$ & $\begin{array}{c}-14(-3) \\
27(0) \\
20(-3) \\
-24(-1) \\
0.71\end{array}$ & $\begin{array}{c}-13(-10) \\
32(0) \\
4(-10) \\
-5(-4) \\
0.77\end{array}$ \\
\hline
\end{tabular}

Примечание. В скобках указаны расчетные данные. Характерные параметры диодов: $I_{\max }, U_{\max }$ - ток и напряжение, соответствующие максимуму; $U^{\prime}$ - пороговое напряжение, при котором появляется заметный ток (после радиационного воздействия); $R_{1}-$ дифференциальное сопротивление начального участка вольт-амперной характеристики; $R_{2}-$ дифференциальное сопротивление участка отрицательной дифференциальной проводимости вольт-амперной характеристики.

Схема импульсного измерительного стенда была рассмотрена подробно в $[8,12]$. В качестве измерительного сигнала использовался колоколообразный импульс (длительность импульса на полувысоте составляла 30 нс, период - 100 мкс, передний фронт импульса был менее 5 нс). Короткий передний фронт позволял регистрировать на осциллографе ВАХ холодной сверхрешетки. Измерения проводились с накоплением результатов по 100 импульсам. За счет низкой $(1 / 2000)$ скважности удавалось избежать даже слабого нагрева исследуемых структур. Отжиг радиационных дефектов с помощью их разогрева протекающим током проводился в течение 5 мин при значении напряжения, подаваемого на диод, равного $2 \mathrm{~B}$, и тока диодов около $25 \mathrm{MA}$.

На рис. 6 представлена типичная вольт-амперная характеристика диодов до и после $\gamma$ - и $\gamma$-нейтронного облучения, а также после дополнительного отжига протекающим током. Отмечены характерные параметры BAX, которые для удобства сравнения сведены в табл. 3. Для отрицательных напряжений смещения BAX диодов подобна приведенным на рис. 6 (см. также вставку на рис. 1).

Из рис. 6 и табл. 1 видно, что расчетные данные подтверждаются экспериментом. Как и предполагалось, амплитуда тока снизилась на $10 \%$ в результате возникновения субкластеров радиационных дефектов. Однако использованная в данной работе математическая модель не смогла предсказать неожиданные изменения ВАХ при низких напряжениях. Возникло пороговое напряжение „отпирания“ диода $U^{\prime}$. Указанное изменение ВАХ диодов скорее всего связано с изменением свойств омических контактов в сторону увеличения их барьерных свойств. В исследованных нами ранее приборах, например, в полевых транзисторах Шоттки и НЕМТ, такого эффекта не наблюдалось. Оказалось, что изменения свойств диода под воздействием излучения гораздо сильнее происходят в области низких напряжений, а не в рабочей области.

По всей видимости, возникновение барьерных свойств контакта металл-полупроводник при малых напряжениях связано с аккумуляцией точечных дефектов на поверхности контактов, что привело к подавлению прово- дящих свойств эвтектики $\mathrm{AuGe}-\mathrm{Au}$ [15]. С одной стороны, такое поведение контактов обсуждалось в литератуpe - характеристики границы металл-полупроводник подвержены некоторому изменению как при $\gamma$-, так и при нейтронном облучении, но для омических контактов это редкость, чаще это наблюдается для барьерных контактов Шоттки [16].

Отметим несколько других важных результатов. Во-первых, влияние $\gamma$-квантов и нейтронов подобно их действию на другие исследованные нами ранее СВЧ диоды и транзисторы - влияние нейтронов проявляется сильнее, чем $\gamma$-квантов. Во-вторых, эксперимент показал слабую зависимость изменений тока диодов от величины дозы, а в некоторых случаях при увеличении дозы облучения влияние радиации уменьшалось. Поскольку изменения параметров диодов, за исключением возникновения порогового напряжения, незначительные, то, скорее всего, это статистический разброс свойств диодов. В-третьих, возникновение порогового напряжения „отпирания“ диода, связанное с изменением свойств его контактов, не приводит к катастрофическому отказу диодов - область отрицательной дифференциальной проводимости на BAX диодов сохраняется, т. е. функционально диод после облучения работоспособен и может использоваться в радиационно стойких детекторах и умножителях терагерцового диапазона частот.

Анализируя результаты эксперимента после отжига радиационных дефектов в диодах из-за разогрева протекающим током, видно, что участок отрицательной дифференциальной проводимости и наклон начального участка ВАX восстановились. Величина тока в максимуме уменьшилась на $2-5 \%$, что не существенно. Порог отпирания диодов по напряжению остался, хотя несколько уменьшился на $0.1-0.3 \mathrm{~B}$.

Моделирование показало, что в целом существенного изменения высокочастотных параметров диодов не происходит вплоть до флюенсов нейтронного облучения $10^{15} \mathrm{~cm}^{-2}$. Из-за наличия областей между кластерами радиационных дефектов, где электроны могут двигаться беспрепятственно от катода к аноду диода, все основные процессы формирования отрицательной диф- 
Таблица 4. Сравнение уровней радиационной стойкости исследуемых диодов с другими СВЧ диодами и транзисторами.

\begin{tabular}{c|c|c|c|c}
\hline \multicolumn{2}{c|}{} & \multicolumn{3}{|c}{ Изменения тока прибора, \% } \\
\cline { 3 - 5 } & & 10 & 30 & 50 \\
\hline Диоды на основе & Расчет & $0.1-0.3 \cdot 10^{14}$ & $1-3 \cdot 10^{14}$ & $5-20 \cdot 10^{14}$ \\
сверхрешеток & Эксперимент & $0.1 \cdot 10^{14}$ & - \\
\hline НЕМТ & Эксперимент [16] & $1-3 \cdot 10^{14}$ & $1-3 \cdot 10^{14}$ & $10-20 \cdot 10^{14}$ \\
Диоды Ганна & Эксперимент [16] & $0.1-0.3 \cdot 10^{14}$ & $0.1-0.3 \cdot 10^{14}$ & $0.2-1 \cdot 10^{14}$
\end{tabular}

ференциальной проводимости остаются неизменными. Значения параметров эквивалентной схемы практически не меняются, так что характерная предельная частота диодов изменяется незначительно. При флюенсах облучения более $10^{15} \mathrm{~cm}^{-2}$ кластеры радиационных дефектов блокируют весь поток электронов и диод откажет.

В табл. 3 представлены изменения параметров диодов после облучения нейтронами и $\gamma$-квантами, где в скобках указаны расчетные данные. Так как воздействие $\gamma$-квантами приводит только к точечным дефектам, то предполагалось, что их влияние на проводимость незначительно и математическая модель их не учитывала. Поэтому в таблице в скобках указаны нули. На сопротивление участка отрицательной дифференциальной проводимости $R_{2}$ влияют только те кластеры радиационных дефектов, которые попали в сверхрешетку, а на сопротивление начального участка ВАX $R_{1}-$ все кластеры, попавшие в активную область диода. Поэтому изменение сопротивления $R_{2}$ меньше, чем $R_{1}$.

Было проведено сравнение экспериментальной и расчетной радиационной стойкости исследуемых диодов с другими известными из литературы приборами, такими как СВЧ полевые транзисторы типа HEMT и диоды Ганна (табл. 4). Также наш расчет с помощью метода Монте-Карло сравнивался с расчетом на основе формул из [5], опирающихся на значение концентрации примесных атомов в диодах. Расчет показал, что использование формул из [5] для исследуемого диода не корректно. Это связано с тем, что в нашем случае нельзя считать дефекты точечными, так как размер кластера радиационных дефектов сравним с размером активной области исследуемого диода, поэтому объемными концентрациями (как доноров, так и дефектов) пользоваться можно только для грубых оценок.

\section{7. Заключение}

Результаты работы позволяют сделать следующие выводы.

1. Влияние облучения $\gamma$-квантами и нейтронами на работу исследованных диодов подобно друг другу, при этом в исследованных интервалах воздействия нет зависимости от величин дозы и флюенса облучения, а в некоторых случаях с увеличением дозы облучение оказывает меньшее влияние. Скорее всего, это стати- стический разброс, поэтому можно считать, что влияние облучения незначительно и функционально диод остается работоспособен. Величина максимального тока после радиационного воздействия с флюенсом $10^{13} \mathrm{H} / \mathrm{cm}^{2}$ и дозой $\gamma$-квантов $10^{4}$ рад снизилась на $10 \%$.

2. После отжига протекающим током участок отрицательной дифференциальной проводимости и наклон начального участка BAX частично восстановились. Величина тока в максимуме уменьшилась на $2-3 \%$, что не существенно. Порог по напряжению уменьшился на $0.1-0.3 \mathrm{~B}$.

3. Параметры элементов эквивалентной схемы диода на основе сверхрешетки после радиационного воздействия при флюенсах нейтронного облучения меньше чем $10^{15} \mathrm{~cm}^{-2}$ меняются незначительно, поэтому предельная частота работы исследуемого диода при таком облучении остается примерно равной 3 ТГц. При флюенсах нейтронного облучения, больших чем $10^{15} \mathrm{~cm}^{-2}$, могут наблюдаться значительные изменения параметров исследуемых диодов.

4. Экспериментально и теоретически получено, что уровень радиационной стойкости исследуемых диодов на основе сверхрешеток сравним или даже выше по сравнению с аналогичными уровнями других СВЧ приборов, известных из литературы.

Работа поддержана грантами РФФИ № 15-02-07935 и МОН РФ (3.3854.2017/4.6).

\section{Список литературы}

[1] С.В. Оболенский. Изв. вузов. Электроника, 6, 67 (2002).

[2] Е.А. Тарасова, Д.С. Демидова, С.В. Оболенский, А.Г. Фефелов, Д.И. Дюков. ФТП, 46 (12), 1587 (2012).

[3] Е.А. Тарасова, А.В. Хананова, С.В. Оболенский, В.Е. Земляков, Ю.Н. Свешников, В.И. Егоркин, В.А. Иванов, Г.В. Медведев, Д.С. Смотрин. ФТП, 50 (3), 331 (2016).

[4] И.Ю. Забавичев, А.А. Потехин, А.С. Пузанов, В.А. Козлов, Е.С. Оболенская, С.В. Оболенский. ФТП, 51 (11), 1489 (2017).

[5] Р. Зулиг. Радиационные эбфекты в ИС на GaAs. Арсенид галлия в микроэлектронике (М., Мир, 1988).

[6] В.А. Козлов, Д.Г. Павельев, А.С. Пузанов, С.В. Оболенский, Е.В. Волкова. ФТП, 49 (12), 1585 (2015).

[7] D.G. Pavelyev, V.A. Kozlov, E.S. Obolenskaya, S.V. Obolensky, V.M. Ustinov, A.P. Vasilev. IEEE Trans. Terahertz Sci. Technol., 8 (2), 231 (2018). 
[8] Д.Г. Павельев, А.П. Васильев, В.А. Козлов, Е.С. Оболенская, С.В. Оболенский, В.М. Устинов. ФТП, 51 (11), 1439 (2017).

[9] Д.Г. Павельев, А.П. Васильев, В.А. Козлов, Ю.И. Кошуринов, Е.С. Оболенская, С.В. Оболенский, В.М. Устинов. ФТП, 50 (11), 1548 (2016).

[10] Д.Г. Павельев, А.П. Васильев, В.А. Козлов, Ю.И. Кошуринов, Е.С. Оболенская, С.В. Оболенский, В.М. Устинов. РЭ, 1, 1 (2016).

[11] Д.Г. Павельев, Н.В. Демарина, Ю.И. Кошуринов, А.П. Васильев, Е.С. Семенова, А.Е. Жуков, В.М. Устинов. ФТП, $38(9), 1141$ (2004).

[12] Е.С. Оболенская, А.Ю. Чурин, С.В. Оболенский, А.В. Мурель, В.И. Шашкин. ФТП, 49 (11), 1507 (2015).

[13] S.V. Obolensky, A.V. Murel, N.V. Vostokov, V.I. Shashkin. IEEE Trans. Electron Dev., 58 (8), 2507 (2011).

[14] J.P. Biersak. Nucl. Instrum. Meth. Phys. Res., 1, 21 (1987).

[15] М. Шур. Современные приборы на основе арсенида галлия (М., Мир, 1991).

[16] Е.А. Ладыгин Е.А. Действие проникающей радиации на изделия электронной техники (М., Сов. радио, 1980).

[17] С.В. Оболенский, Н.В. Демарина. Наука - производству, 12, 12 (1998).

[18] Ф.П. Коршунов, Г.В. Гатальский, Г.М. Иванов. Радиационные эбббекты в полупроводниковых приборах (Минск. Наука и техника, 1978).

[19] В.Т. Громов, М.А. Китаев, Е.В. Киселева, В.А. Козлов, С.В. Оболенский, В.П. Шукайло. Микроэлектроника, 34 (6), 424 (2005).

[20] Е.В. Киселева, С.В. Оболенский, М.А. Китаев, О.В. Ткачев, В.П. Шукайло, В.Т. Громов. ЖТФ, 20 (31), 58 (2005).

[21] B.R. Gossik. J. Appl. Phys., 9, 1214 (1954).

[22] С.В. Оболенский С.В. Изв. вузов. Электроника, 6, 67 (2002).

Редактор Г.А. Оганесян

\section{Radiation hardness of terahertz diode based on GaAs/AlAs-superlattices}

D.G. Pavelyev' ${ }^{1}$, A.P. Vasilev' ${ }^{2}$, V.A. Kozlov ${ }^{1,3}$, E.S. Obolenskaya ${ }^{1}$

${ }^{1}$ Lobachevsky State University of Nizhny Novgorod, 603950 Nizhny Novgorod, Russia

2 Submicron Heterostructures for Microelectronics, Research \& Engineering Center, Russian Academy of Sciences, 194021 St. Petersburg, Russia

${ }^{3}$ Institute for Physics of Microstructures, Russian Academy of Sciences 603087 Nizhny Novgorod, Russia

Abstract The radiation resistance to gamma-neutron irradiation of diodes based on symmetric GaAs/AlAs 30-period superlattices (SL) was first theoretically and experimentally investigated. For the calculations, the refined band diagram and equivalent circuit of the structure were used. The calculations were performed in the quasi-hydrodynamic approximation with allowance for the heating of the investigated diodes by flowing current. The results of calculations of the $I-V$ characteristics and the limiting frequencies of the diodes before and after gamma-neutron irradiation correlate well with experimental data. 